\title{
Primary sclerosing epithelioid fibrosarcoma of the sacrum: a case report and review of the literature
}

\author{
L T C Chow, Y H Lui, S M Kumta, P W Allen
}

J Clin Pathol 2004;57:90-94

Sclerosing epithelioid fibrosarcoma is a rare tumour characterised histologically by a predominant population of epithelioid cells arranged in strands and nests, embedded in a fibrotic and hyalinised stroma. It is a low grade tumour with an indolent course. A 48 year old woman presented with a painful swelling over her back for six months. Investigation and biopsy revealed features of sclerosing epithelioid fibrosarcoma involving the left half of the sacrum, left sacro-iliac joint, and posterior part of the left ilium. Preoperative radiotherapy and wide location excision of the tumour were followed by metastatic recurrence of the tumour in the lung and scalp six years after initial presentation. The tumour showed typical histology of sclerosing epithelioid fibrosarcoma. The radiological features confirmed its primary location in the sacrum. The patient declined chemotherapy and died of disseminated disease eight years after initial presentation. Review of the literature confirms the fact that sclerosing epithelioid fibrosarcoma, despite its low grade, is a clinicopathologically distinct tumour with full malignant potential, the recurrence, metastasis, and mortality rate being $48 \%, 60 \%$, and $35 \%$, respectively. Sclerosing epithelioid fibrosarcoma can occur as a primary bone tumour, the clinical behaviour of which is probably similar to its soft tissue counterpart.

S clerosing epithelioid fibrosarcoma is a rare tumour characterised histologically by a predominant population of epithelioid cells arranged in strands, nests, and sheets, embedded in a fibrotic and extensively hyalinised stroma. It was first described in 1995 by Meis-Kindblom and colleagues $^{1}$ as a distinct and rare tumour of the soft tissue, occurring primarily in the deep musculature and frequently associated with the adjacent fascia or periosteum. In their report, the tumours were mostly located in the lower extremities and limb girdles, trunk, and less commonly, in upper limb girdles and neck. From their series of 25 patients, the authors concluded that it is a low grade fibrosarcoma that pursues an indolent course, although four of their patients died of the disease 3.1 to 13.7 years after diagnosis. Following their description, there were a few series and case reports validating their findings. ${ }^{2-12}$

In this article, we report a patient with sclerosing epithelioid fibrosarcoma arising from the sacrum, and its clinical course is described and compared with that in the soft tissue.

\section{CASE REPORT}

\section{Clinical history}

The patient, a 48 year old female garment factory worker, first presented in October 1995 with a swelling over the lower back for six months. The swelling progressively increased in size and became painful. She had no constitutional symptoms, had previously been in good health, and denied a history of trauma to the region.

Physical examination revealed an ill defined bony mass over the region of the left sacro-iliac joint, approximately $6 \times 6 \mathrm{~cm}$ across. It was fixed to the underlying bone but not to the skin. There was mild local tenderness and the sacroiliac joint stretch test was painful. Per rectal and vaginal examinations were normal.

Plain $x$ ray of the pelvis showed a vague shadow in the region of the left sacro-iliac joint with destruction of part of the sacrum. A computerised tomography scan showed a large lobulated tumour arising from the left half of the sacrum, $5 \times 8 \times 8 \mathrm{~cm}$, involving the left sacro-iliac joint and the posterior portion of the left ilium. The tumour also eroded through the cortex, with extension into the adjacent soft tissue both anteriorly and posteriorly (fig 1). A bone scan showed decreased activity in the left lower sacrum, but there was rim-like increased activity around the tumour, consistent with reactive changes. The chest radiograph was normal. Percutaneous biopsy of the tumour was performed and showed features of sclerosing epithelioid fibrosarcoma.

The patient was treated with preoperative radiotherapy, consisting of 5000 Gray given over a period of six weeks, followed by wide local excision. The tumour, together with the sacrum, part of the left sacro-iliac joint, and posterior ilium, was resected. The postoperative course was uneventful and the patient resumed her usual daily activities after four months of rehabilitation. She remained well five years after surgery.

In May 2001, a few lung nodules were detected in her chest radiograph, consistent with metastasis (fig 2). At the same time, the patient also noticed a nodule over the scalp, and because it continued to increase in size slowly, an excisional biopsy was performed, and showed features consistent with metastatic sclerosing epithelioid fibrosarcoma. Chemotherapy was offered but declined by the patient and her family. The scalp nodule recurred in December 2001 and was resected, and the histology was similar to that of the initial one. The patient died of disseminated disease with metastatic lesions in the lung, liver, scalp, and retroperitoneum eight years after initial presentation.

\section{Pathological examination}

The initial biopsy showed fragments of light to dark brown tissue with bony areas, measuring $1 \times 2 \times 3 \mathrm{~cm}$ in aggregate. The resected specimen consisted of a multiloculated tumour arising from the sacrum, $5.5 \times 10 \times 12 \mathrm{~cm}$ in maximal dimension, together with a portion of the left sacro-iliac joint and a small posterior part of the left ilium.

Abbreviations: EMA, epithelial membrane antigen; LCA, leucocyte common antigen 


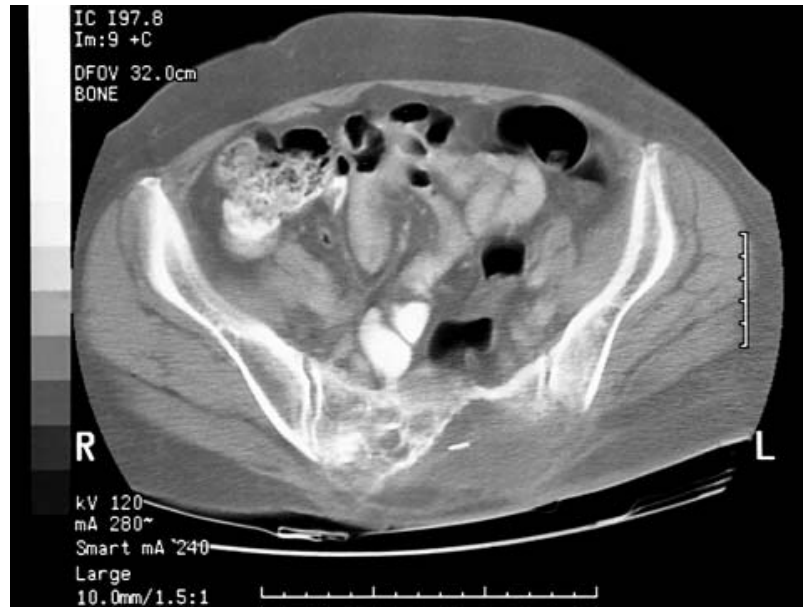

Figure 1 Computerised tomography scan of the patient, showing the tumour arising from the sacrum and involving the sacro-iliac joint and the posterior part of the ilium.

Cut section of the tumour showed a light yellow firm surface (fig 3A). The histological features of both the biopsy and resected specimen were similar.

The tumour was poorly circumscribed and showed an infiltrative edge, with destruction of the surrounding lamellar cortical bone (fig 3B). Most of the tumour was of low cellularity but scattered throughout were more cellular areas. The tumour cells showed a monomorphic appearance, they were rounded, oval, or polygonal, of small to medium size, and with clear or pale eosinophilic cytoplasm. They were arranged in cords, strands, and clusters or in single isolations, and were surrounded by a variable amount of dense collagenous stroma with areas of hyalinisation (fig 3B). The nuclei of the tumour cells were small, ovoid, or angular, and mostly pale or vesicular, with distinct nucleoli and little pleomorphism (fig 3C). Some of the tumour cells showed clear or vacuolated cytoplasm (fig 3D), but they constituted less than $20 \%$ of the tumour. Mitotic figures were infrequent, less than one for each 10 high power fields. Necrosis was absent. Areas showing features of conventional fibrosarcoma were not seen. The resection margins were free of tumour.

Immunohistochemically, apart from the diffuse positive staining for vimentin (1/20 dilution; Dako, Glostrup, Denmark), the tumour cells showed negative staining for all other markers, including epithelial membrane antigen (EMA; 1/50 dilution; Dako, Ely, UK), AEl/AE3 (1/200 dilution; Biogenex, Upton on Seven, UK), CAM5.2 (1/20 dilution; Becton-Dickinson, Oxford, UK), S100 (1/1000 dilution; Dako UK), HMB45 (1/50 dilution; Dako UK), desmin (1/50 dilution; Dako UK), CD34 (1/50 dilution; Dako UK), MIC-2/CD99 (1/50 dilution; Dako UK), and leucocyte common antigen (LCA; 1/20 dilution; Dako UK).

On electron microscopy, the tumour cells showed either irregular nuclei or oval nuclei with a smooth outline, and paranuclear aggregates of intermediate filaments were noted. Rough endoplasmic reticulum was not prominent and there was no complete basal lamina.

The overall clinical, radiological, gross, histological, immunohistochemical, and ultrastructural features were those of sclerosing epithelioid fibrosarcoma arising from the sacrum.

\section{DISCUSSION}

Sclerosing epithelioid fibrosarcoma is a clinicopathologically distinct tumour of the soft tissue first described by MeisKindblom et al in $1995 .{ }^{1}$ The tumour occurs mostly in the deep musculature and is frequently associated with the

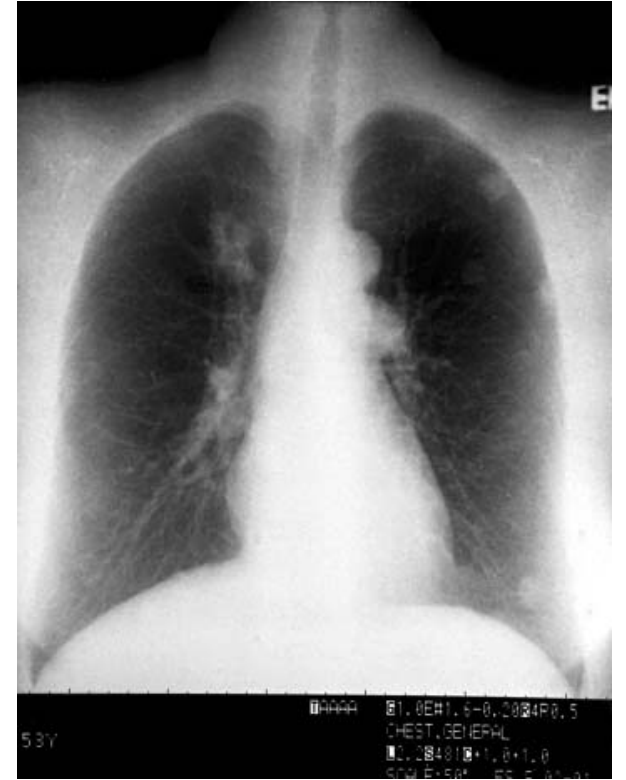

Figure 2 Multiple nodules are present in the chest radiograph, consistent with metastatic involvement of the lung.

adjacent fascia or periosteum. It is characterised histologically by a proliferation of uniform, small, slightly angulated, round to oval epithelioid cells with sparse, often clear cytoplasm arranged in nests and cords, associated with prominent hyaline sclerosis of the stroma. There may be myxoid areas with cyst formation, foci of hyaline cartilage, calcification, and metaplastic bone. Most of the tumours show positive staining for vimentin, but variable staining for EMA, S100 protein, CAM5.2, and AE1/AE3. Ultrastructurally, the tumour cells contain a network of intermediate cytofilaments and moderate numbers of mitochondria intimately associated with rough endoplasmic reticulum. The features are consistent with those of fibroblastic/myofibroblastic differentiation.

In their series of 25 patients, information regarding survival was available in 16 cases, and six patients showed no evidence of disease at a follow up period of 13 to 204 months. Eight of 15 patients suffered from local recurrences, the time of first recurrences from initial diagnosis ranged from 28 to 132 months. Six of 14 patients developed distant metastases at an interval of 56 to 168 months. Four of these 16 patients died of the disease 37 to 164 months after presentation. They concluded that sclerosing epithelioid fibrosarcoma is a distinctive soft tissue sarcoma that behaves in a relatively low grade manner.

Their findings were largely validated by subsequent reports by others. ${ }^{2-12}$ In particular, in the recent series of 16 patients by Antonescu et al, ${ }^{9}$ the authors concluded that sclerosing epithelioid fibrosarcoma is a clinicopathologically distinct low grade fibrosarcoma that is closely related to low grade fibromyxoid sarcoma ${ }^{13-15}$ and hyalinising spindle cell tumour with giant rosettes. ${ }^{16-20}$ These three tumours belong to the same family of so called "fibrosing fibrosarcomas", which are sarcomas that exhibit fibroblastic differentiation and show prominent widespread fibrosis readily evident both grossly and microscopically.

Even though the incidence of persistent disease and local recurrences in the series of Antonescu et al (57\%) is similar to that of Meis-Kindblom et al (50\%), Antonescu et al observed a shorter mean interval to first local recurrence $(22.6 v 71.5$ months). Furthermore, the metastasis and mortality rates in the series of Antonescu et al (86\% and 57\%) are also 

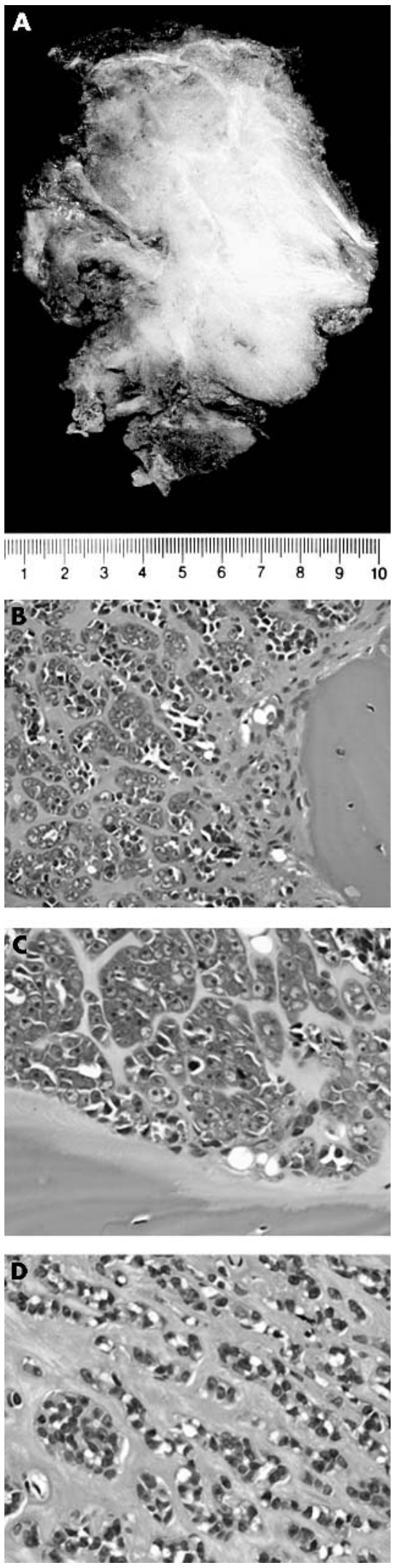

Figure 3 (A) Cut surface of the tumour shows light yellow firm tissue. (B) Histologically, the tumour has a monotonous appearance, consisting of polygonal cells arranged in cords, strands, and clusters, surrounded by dense collagenous stroma with areas of hyalinisation. The tumour infiltrates into the surrounding cortical lamellar bone. (C) High power magnification to show the morphology of the tumour cells. They are rounded, oval, or polygonal, of small to medium size, and with clear or pale eosinophilic cytoplasm. The nuclei of the tumour cells are small, ovoid, or angular, and mostly pale or vesicular, with distinct nucleoli and little pleomorphism. (D) Some of the tumour cells show clear or vacuolated cytoplasm, but they constitute less than $20 \%$ of the tumour. significantly higher than those of Meis-Kindblom et al $(43 \%$ and $25 \%$ ). One of the possible explanations for this difference is that the tumours in three of the 16 cases of Antonescu et al involved the cranium, and it has been speculated that sclerosing epithelioid fibrosarcomas of the neuraxis may behave more aggressively than those arising in the deep skeletal muscles. ${ }^{7}$ Indeed, two of the three patients with involvement of the cranium in the series of Antonescu et al died of their disease. ${ }^{9}$

"Sclerosing epithelioid fibrosarcoma, despite its low grade, is a clinicopathologically distinct soft tissue tumour with full malignant potential, with the recurrence, metastasis, and mortality rates being $48 \%, 60 \%$, and $35 \%$, respectively"

Another point of interest is that histological evidence of tumour necrosis was noted in six of the 16 cases reported by Antonescu et al. In two of these six patients, the necrosis was also detected macroscopically; the patient with $50 \%$ necrosis died of the disease at 86 months, and the other with 30\% necrosis had a follow up period of only two months. In contrast, none of the tumours in the series of Meis-Kindblom et al involved the cranium or showed necrosis. In this regard, it is also of interest to note that in a recently reported case of sclerosing epithelioid fibrosarcoma by Hanson et al, ${ }^{10}$ not only did the tumour exhibit large areas of necrosis (45\%), but there were also areas of high grade nuclear anaplasia and active mitosis. The tumour recurred 10 months after surgery and there was disseminated metastasis to the lumbar spine, liver, and peritoneum. High grade areas were also seen in the recurrent tumour and peritoneal metastasis. The patient died 12 months after initial presentation. Accordingly, the prognostic implication of the various clinicopathological parameters, notably the location and histomorphology of the tumour, deserves further detailed analysis.

Review of the English literature shows that a total number of 57 cases of sclerosing epithelioid fibrosarcoma have been reported (table 1). Follow up information was available in 44 patients. The cumulative data fully support the notion that sclerosing epithelioid fibrosarcoma, despite its low grade, is a clinicopathologically distinct soft tissue tumour with full malignant potential, with the recurrence, metastasis, and mortality rates being $48 \%, 60 \%$, and $35 \%$, respectively (table 2).

In addition to the usual occurrence in the deep muscular compartment, Bilsky and colleagues ${ }^{7}$ and Antonescu and colleagues ${ }^{9}$ identified a group of patients with tumour principally involving the cranium and intracranial contents. Antonescu et al also noted bone invasion by sclerosing epithelioid fibrosarcoma in six of their 16 patients. However, primary sclerosing epithelioid fibrosarcoma affecting the bone is distinctly rare and only one recent report ${ }^{12}$ is found in the English literature. The case concerns a 42 year old woman with a 13 year history of a "stable lesion" in the left iliac bone. Biopsy of the lesion at that time was interpreted as necrosis with fibrosis and reactive changes. Unfortunately, the lesion assumed an aggressive radiological appearance three years later, and a tumour of the scalp was also detected. Biopsy of the bone lesion and resection of the scalp tumour showed histological features of sclerosing epithelioid fibrosarcoma. The patient remained alive with lung metastasis two years after the diagnosis.

The radiological appearances of the tumour in our patient fully document that it primarily originates from and involves the sacrum, an opinion endorsed by JM Mirra (personal communication, 1996). The gross morphology, histology, immunohistochemical staining pattern, and ultrastructural 
Table 1 Summary of the clinical presentation of the cases of sclerosing epithelioid fibrosarcoma reported in the literature

\begin{tabular}{|c|c|c|c|c|c|c|c|}
\hline \multirow[b]{2}{*}{ Series/Case report } & \multirow{2}{*}{$\begin{array}{l}\text { Number of } \\
\text { patients (males; } \\
\text { females) }\end{array}$} & \multirow[b]{2}{*}{$\begin{array}{l}\text { Age range } \\
\text { (years) }\end{array}$} & \multicolumn{4}{|c|}{ Location of tumour } & \multirow[b]{2}{*}{$\begin{array}{l}\text { Duration of } \\
\text { symptoms }\end{array}$} \\
\hline & & & $\begin{array}{l}\text { Head and } \\
\text { neck }\end{array}$ & Upper limb & Lower limb & Trunk & \\
\hline Meis-Kindblom et al (1995)' & 25 (14M; 11F) & $14-87$ & 2 & 2 & 12 & 9 & Months to years \\
\hline Reid et al $(1996)^{2}$ & 1 (M) & 40 & 0 & 0 & 1 & 0 & 18 months \\
\hline Christensen et al $(1997)^{3}$ & $1(\mathrm{M})$ & 37 & 0 & 0 & 1 & 0 & 6 months \\
\hline Eyden et al $(1998)^{4}$ & $5(1 \mathrm{M} ; 4 \mathrm{~F})$ & $23-74$ & 3 & 0 & 0 & 2 & Not stated \\
\hline Gisselsson et al $(1998)^{5}$ & $1(\mathrm{M})$ & 14 & 0 & 0 & 1 & 0 & Not stated \\
\hline Donner et al $(2000)^{6}$ & $1(\mathrm{M})$ & 55 & 0 & 0 & 1 & 0 & 4 years \\
\hline Bilsky et al $(2000)^{7}$ & $3(3 F)$ & $14-52$ & 2 & 0 & 0 & 1 & 8 months -13 years \\
\hline Arya et al $(2001)^{8}$ & $1(M)$ & 55 & 0 & 0 & 0 & 1 & 4 months \\
\hline Antonescu et al $(2001)^{9}$ & 16 (6M; 10F) & $14-55$ & 5 & 4 & 3 & 4 & Months to 13 years \\
\hline Hanson et al $(2001)^{10}$ & 1 (M) & 54 & 0 & 0 & 0 & 1 & 3 months \\
\hline Jiao et al $(2002)^{11}$ & $1(F)$ & 75 & 0 & 0 & 0 & 1 & 20 months \\
\hline Abdulkader et al $(2002)^{12}$ & $1(\mathrm{~F})$ & 42 & & & & 1 & 16 years \\
\hline Cumulative data & 57 (27M; 30F) & $14-87$ & 12 & 6 & 19 & 20 & Months to 16 years \\
\hline
\end{tabular}

appearances of the tumour are highly characteristic of sclerosing epithelioid fibrosarcoma. Accordingly, our patient is the second reported case of primary sclerosing epithelioid fibrosarcoma of the bone. The patient remained well and free of disease five years after complete surgical removal of the tumour. However, she presented with metastasis involving the scalp and lung six years after surgery. She finally died of disseminated disease with metastasis to the lung, liver, scalp, and retroperitoneum eight years after initial presentation.

It is of interest that both our case of primary osseous sclerosing epithelioid fibrosarcoma and that reported by Abdulkader et al affected the iliac bone, and occurred in middle aged female patients. Furthermore, the tumours in both patients pursued an indolent but aggressive clinical course, with metastasis to the lung and scalp. Our patient finally succumbed eight years after initial presentation.

The spectrum of differential diagnosis of sclerosing epithelioid fibrosarcoma is broad, as reflected in the diagnoses offered by the referring pathologists in the series of patients reported by Meis-Kindblom et al. ${ }^{1}$ The bland cytology of the tumour cells and the hyalinised stroma raise the possibility of benign lesions such as desmoid tumour, fibrous histiocytoma, and hyalinised leiomyoma. However, the epithelioid appearance of the tumour cells in our case, together with their pale eosinophilic or clear cytoplasm, and arrangement in infiltrative cords or strands, are typical of sclerosing epithelioid fibrosarcoma and allow its ready differentiation from desmoid and fibrous histiocytoma. The negative staining for desmin distinguishes sclerosing epithelioid fibrosarcoma from a hyalinised leiomyoma. The malignant diagnostic considerations include infiltrating carcinoma, monophasic synovial sarcoma, clear cell sarcoma (malignant melanoma of soft part), myxoid chondrosarcoma, and sclerosing lymphoma. The negative staining of the tumour cells in our case for CAM5.2, AE1/AE3, EMA, S100, HMB45, and LCA argues against the aforementioned diagnoses. In fact, the histological pattern of our case, in combination with the sole positive staining for vimentin and electron microscopic features of fibroblastic differentiation, fulfil the strict diagnostic criteria of sclerosing epithelioid fibrosarcoma proposed by Eyden et al. ${ }^{4}$

In conclusion, sclerosing epithelioid fibrosarcoma can occur as a primary tumour in the bone, and from the clinical course of our patient and the patient reported by Abdulkader et al, we speculate that its behaviour is similar to its soft tissue counterpart. Whenever possible, wide local resection should be carried out because there is no clear evidence to support the use of adjuvant treatment alone in this rare tumour.

Table 2 Summary of the clinical outcomes of the cases of sclerosing epithelioid fibrosarcoma reported in the literature

\begin{tabular}{|c|c|c|c|c|c|c|}
\hline Series/Case report & $\begin{array}{l}\text { Patients with } \\
\text { follow up }\end{array}$ & $\begin{array}{l}\text { Duration of follow } \\
\text { up }\end{array}$ & $\begin{array}{l}\text { No evidence of } \\
\text { disease (\%; duration) }\end{array}$ & $\begin{array}{l}\text { Recurrence }(\% ; \\
\text { time from Dx) }\end{array}$ & $\begin{array}{l}\text { Metastasis (\%; } \\
\text { time from Dx) }\end{array}$ & $\begin{array}{l}\text { Death }(\% ; \text { time } \\
\text { from } D x)\end{array}$ \\
\hline Meis-Kindblom et al (1995)' & 16 & 13-207 months & $\begin{array}{l}\text { 6/16 (37\%; } \\
13-204 \text { months) }\end{array}$ & $\begin{array}{l}8 / 15 \text { (53\%; } \\
28-132 \text { months) }\end{array}$ & $\begin{array}{l}\text { 6/14 (43\%; } \\
56-168 \text { months) }\end{array}$ & $\begin{array}{l}4 / 16 \text { (25\%; } \\
37-164 \text { months) }\end{array}$ \\
\hline Reid et al $(1996)^{2}$ & 1 & 96 months (AWD) & 0 & 0 & 1 (60 months) & 0 \\
\hline Christensen et al $(1997)^{3}$ & NA & NA & NA & NA & NA & NA \\
\hline Eyden et al $(1998)^{4}$ & 4 & 4-84 months & $\begin{array}{l}2 / 4 \text { (50\%; } 4-36 \\
\text { months) }\end{array}$ & $\begin{array}{l}2 / 4(50 \% ; \\
10-24 \text { months) }\end{array}$ & $\begin{array}{l}1 / 4(25 \% ; \text { not } \\
\text { stated) }\end{array}$ & $\begin{array}{l}1 / 4 \text { (25\%; } 84 \\
\text { months) }\end{array}$ \\
\hline Gisselsson et al $(1998)^{5}$ & 1 & 24 months (AWD) & 0 & 1 (24 months) & 0 & 0 \\
\hline Donner et al $(2000)^{6}$ & 1 & 14 months & 1 (14 months) & 0 & 0 & 0 \\
\hline Bilsky et al $(2000)^{7}$ & 3 & $12-59$ months & $0 / 3(0 \%)$ & $\begin{array}{l}2 / 3 \text { (67\%; } \\
10-13 \text { months) }\end{array}$ & $\begin{array}{l}3 / 3 \text { (100\%; } \\
0-36 \text { months) }\end{array}$ & $\begin{array}{l}1 / 3 \text { (33\%; } 59 \\
\text { months) }\end{array}$ \\
\hline Arya ef al $(2001)^{8}$ & 1 & 48 months & 1 (48 months) & 0 & 0 & 0 \\
\hline Antonescu et al (2001) & 14 & $13-124$ months & $\begin{array}{l}1 / 14 \text { (7\%; } 13 \\
\text { months) }\end{array}$ & $\begin{array}{l}7 / 14 \text { (50\%; } \\
2-46 \text { months) }\end{array}$ & $\begin{array}{l}\text { 12/14 (86\%; } \\
0-102 \text { months) }\end{array}$ & $\begin{array}{l}8 / 14 \text { (57\%; } \\
13-86 \text { months) }\end{array}$ \\
\hline Hanson et al $(2001)^{10}$ & 1 & 12 months & 0 & 0 & 1 (1.5 months) & 1 (12 months) \\
\hline Jiao et al $(2002)^{11}$ & 1 & 20 months & 1 (20 months) & 0 & 0 & 0 \\
\hline Abdulkader et al (2002) ${ }^{12}$ & 1 & 60 months & 0 & 0 & 1 (36 months) & 0 \\
\hline Cumulative data & 44 & 4-207 months & $\begin{array}{l}\text { 12/43 (28\%; } \\
13-204 \text { months) }\end{array}$ & $\begin{array}{l}20 / 42 \text { (48\%; } \\
2-132 \text { months) }\end{array}$ & $\begin{array}{l}25 / 42 \text { (60\%; } \\
0-168 \text { months) }\end{array}$ & $\begin{array}{l}\text { 15/43 (35\%; } \\
12-164 \text { months) }\end{array}$ \\
\hline
\end{tabular}

AWD, alive with disease; Dx, diagnosis; NA, not available. 


\section{Take home messages}

- We report the second case of primary osseous sclerosing epithelioid fibrosarcoma

- The clinical behaviour of this rare tumour appears to be similar to its soft tissue counterpart

- The tumour pursued an indolent but aggressive clinical course, with metastasis to the lung and scalp

- Whenever possible, wide local resection should be carried out because there is no clear evidence to support the use of adjuvant treatment alone

\section{ACKNOWLEDGEMENTS}

The authors thank Dr J M Mirra for reviewing the case and agreeing that the tumour originates from bone.

\section{Authors' affiliations}

Lovis T C Chow, Department of Anatomical and Cellular Pathology, Prince of Wales Hospital, 30-32, Ngan Shing Street, Shatin, Hong Kong Y H Lui, Department of Pathology, United Christian Hospital, Hong Kong S M Kumta, Department of Orthopaedics and Traumatology, Prince of Wales Hospital

P W Allen, Department of Anatomical and Cellular Pathology, Flinders Medical Centre, South Australia 5042

Correspondence to: $\operatorname{Dr}$ L T C Chow, Department of Anatomical and Cellular Pathology, Prince of Wales Hospital, 30-32, Ngan Shing Street, Shatin, Hong Kong; Ichow@cuhk.edu.hk

Accepted for publication 10 July 2003

\section{REFERENCES}

1 Meis-Kindblom JM, Kindblom LG, Enzinger FM. Sclerosing epithelioid fibrosarcoma: a variant of fibrosarcoma simulating carcinoma. Am J Surg Pathol 1995; 19:979-93.

2 Reid R, Barrett A, Hamblen DL. Sclerosing epithelioid fibrosarcoma. Histopathology 1996;28:451-5.
3 Christensen DR, Ramsamooi R, Gilbert TJ Sclerosing epithelioid fibrosarcoma: short T2 on MR imaging. Skeletal Radiol 1997;26:619-21.

4 Eyden BP, Manson C, Banerjee SS, et al. Sclerosing epithelioid fibrosarcoma: a study of five cases emphasizing diagnostic criteria. Histopathology 1998:33:354-60.

5 Gisselsson D, Andreasson P, Meis-Kindblom JM, et al. Amplification of 12q13 and 12 q15 sequences in sclerosing epithelioid fibrosarcoma. Cancer Genet Cytogenet 1998;107:102-6.

6 Donner LR, Clawson K, Dobin SM. Sclerosing epithelioid fibrosarcoma: a cytogenetic, immunohistochemical, and ultrastructural study of an unusual histological variant. Cancer Genet Cytogenet 2000;1 19:127-31.

7 Bilsky MH, Schefler AC, Sandberg DI, et al. Sclerosing epithelioid fibrosarcomas involving the neuraxis: report of three cases. Neurosurgery 2000;47:956-60.

8 Arya M, Garcia-Montes F, Patel HR, et al. A rare tumour in the pelvis presenting with lower urinary symptoms: "sclerosing epithelioid fibrosarcoma". Eur J Surg Oncol 2001;27:121-2.

9 Antonescu CR, Rosenblum MK, Pereira $\mathrm{P}$, et al. Sclerosing epithelioid fibrosarcoma: a study of 16 cases and confirmation of a clinicopathologically distinct tumor. Am J Surg Pathol 2001;25:699-709.

10 Hanson IM, Pearson JM, Eyden BP, et al. Evidence of nerve sheath differentiation and high grade morphology in sclerosing epithelioid fibrosarcoma. J Clin Pathol 2001;54:721-23.

11 Jiao YF, Nakamura S, Sugai T, et al. Overexpression of MDM2 in a sclerosing epithelioid fibrosarcoma: genetic, immunohistochemical and ultrastructural study of a case. Pathol Int 2002;52:135-40

12 Abdulkader I, Cameselle-Teijeiro J, Fraga M, et al. Sclerosing epithelioid fibrosarcoma primary of the bone Int I Surg Pathol 2002:10:227-30.

13 Evans HL. Low grade fibromyxoid sarcoma. A report of two metastasizing neoplasms having a deceptively benign appearance. Am J Clin Pathol 1987;88:615-19.

14 Evans HL. Low grade fibromyxoid sarcoma. A report of 12 cases. Am J Surg Pathol 1993:17:595-600.

15 Goodlad JR, Mentzel T, Fletcher CDM. Low grade fibromyxoid sarcoma: a clinicopathologic analysis of 11 new cases in support of distinct entity. Histopathology 1995;26:229-37.

16 Lane KL, Shannon RK, Weiss SW. Hyalinizing spindle cell tumor with giant rosettes: a tumor closely resembling low-grade fibromyxoid sarcoma. Am J Surg Pathol 1997;21:1481-8.

17 Nielsen GP, Selig MK, O'Connell JX, et al. Hyalinizing spindle cell tumor with giant rosettes: a report of three cases with ultrastructural analysis. Am J Surg Pathol 1999:23:1227-32.

18 Woodruff JM, Antonescu CR, Erlandson RA, et al. Low-grade fibrosarcoma with palisaded granuloma-like bodies (giant rosettes): report of a case that metastasized. Am J Surg Pathol 1999;23:1423-8.

19 Farinha P, Oliveira P Soares J. Metastasizing hyalinizing spindle cell tumor with giant rosettes: report of a case with long survival. Histopathology 2000;36:92-3

20 Folpe AL, Lane KL, Paull G, et al. Low grade fibromyxoid sarcoma and hyalinizing spindle cell tumor with giant rosettes. A clinicopathologic study of 73 cases supporting their identity and assessing impact of high grade areas. Am J Surg Pathol 2000;24:1353-60. 